\title{
Active and Reactive Power Control of a Variable Speed Wind Energy Conversion System based on Cage Generator
}

\author{
Mazhar Hussain Baloch ${ }^{1}$ \\ ${ }^{1}$ Department of Electrical \\ Engineering, MUET Khairpur Mir's \\ Campus Pakistan
}

\author{
Waqas Ahmed Wattoo ${ }^{2}$ \\ ${ }^{2}$ Department of Electrical \\ Engineering, \\ COMSAT Pakistan
}

\author{
Dileep Kumar ${ }^{3}$ \\ ${ }^{3}$ Department of Electronics \\ Engineering, the Islamia University \\ of Bahawalpur, Pakistan \\ Ghulam Sarwar Kaloi ${ }^{4}$ \\ ${ }^{4}$ Department of Electrical \\ Engineering QUCEST Larkana \\ Sindh Pakistan
}

\author{
Ali Asghar Memon ${ }^{5}$ \\ ${ }^{5}$ Department of Electrical \\ Engineering, \\ MUET Jamshoro Campus Pakistan \\ Sohaib Tahir $^{6}$
${ }^{6}$ Department of Electrical
Engineering,
COMSAT Pakistan
}

\begin{abstract}
This manuscript presents the modeling and control design for a variable speed wind energy conversion system (VSWECS). This control scheme is based on three-phase squirrel cage induction generator driven by a horizontal-axis wind turbine through the overhead transmission network. In this manuscript, a static VAR compensator is proposed and connected with the squirrel cage induction generator terminals in order to regulate the system parameters, such as voltage, power. Through the pitch angle, the mechanical power was controlled through Simulink (Matlab) software. From the simulation results, the response of the proposed system offers good robustness and fast recovery under various dynamic system disturbances.
\end{abstract}

\section{Keywords-VAR compensator; wind turbine; cage generator}

\section{INTRODUCTION}

Utilization of fossil fuels for conventional power generation creates an environmental alarm thus diverts stakeholder's interests to renewable resources. This renewable sources offer limitless availability and cause a hazardous effect on the environment. Therefore, various renewable energy power generation methods are available in order to minimize the hazardous effects in which wind energy conversion system is the most noteworthy form and is widely utilized among the new power generation sources in the world [1]-[2]. For that reason, wind energy is clean, free source, geographically available, and particularly valuable in bucolic regions [16]. Fundamentally, wind energy can be well defined as to transforms the kinetic energy of wind pressure available in the atmosphere into electricity through a turbine and a generator [3]. What's more, globally, under an advanced growth in 2014 the wind power installed capacity was increased from the previous years as shown in Fig 1 and the top few countries as shown in Fig. 2 (see [17]-[19]). The optimal exploitation of wind energy potential is an exigent problem for researchers, engineers and scientists, provided the erratic nature of wind circumstances. However, this is the hot research direction now-a-days, the emphasis is on the cost effective exploitation regarding power quality and reliability. In addition, nowadays researchers are taking a keen interest in extracting dominant possible wind energy potential in order to produce the electricity [4]-[6]. Overall wind potential efficiency considerably increases when executing at variable speed. Whereas, variable wind speed has more advantages as compared with conventional wind speed [7]. At this moment, advanced control techniques are primarily needed for stability and control purpose for WECS. In this paper, our study is focused on the compensation of wind energy conversion system parameters due to the variation of wind speed, and composed of a wind turbine and a 3-phase generator established on field oriented control concept. Control of the generator has attracted considerable attention in the last few decades. This type of generator is globally well-known among all generators, and presents numerous advantages for wind energy applications such as relatively cheap, robust, and needs diminutive maintenance compared with other types of generator. Furthermore, when squirrel cage generators are operated with sensor-less control concepts, a quick and perfect torque response is obtained [8]-[9]. As referring to [10]-[11], various simulation models of wind turbine system for stability and control methods were designed and integrated with the power system arrangement. However, the wind turbine controller requires redesign carefully for WECS because many model-dependent designs have some drawbacks. As referring to [12], authors presented the controller for wind turbine system, but different from our proposed model in several characteristics, including suppositions and robustness. The prime objectives for the control design of WECS are not only optimal power but also improve the dynamic system characteristics. As a result, the VAR compensation approaches are simple, reduction in output power fluctuations and have a rapid response by ignoring magnetic saturation of the induction generator. Moreover, the proposed technique is the most up-to-date effort having better performance and robustness, endure for wind turbine system stability and power compensation under unstable wind circumstances. 


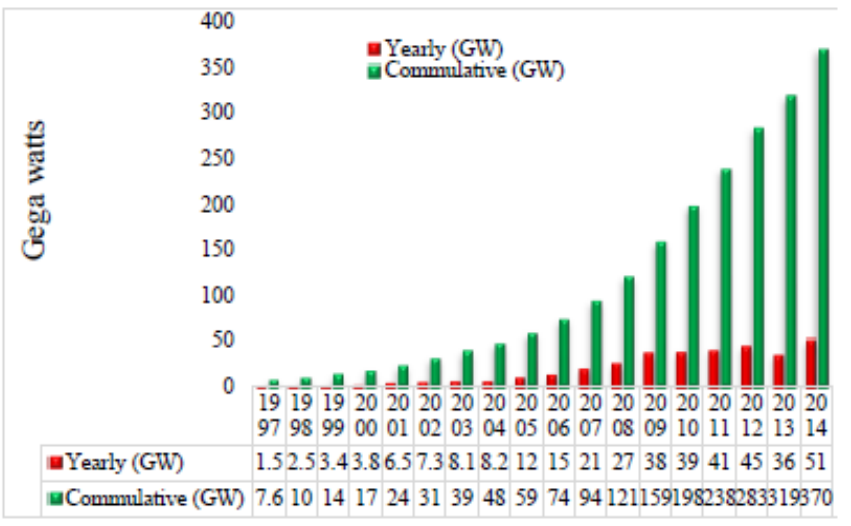

Fig. 1. Global total installed wind energy capacity since 1997-2014 [P. Mozumder et.al., 2007].

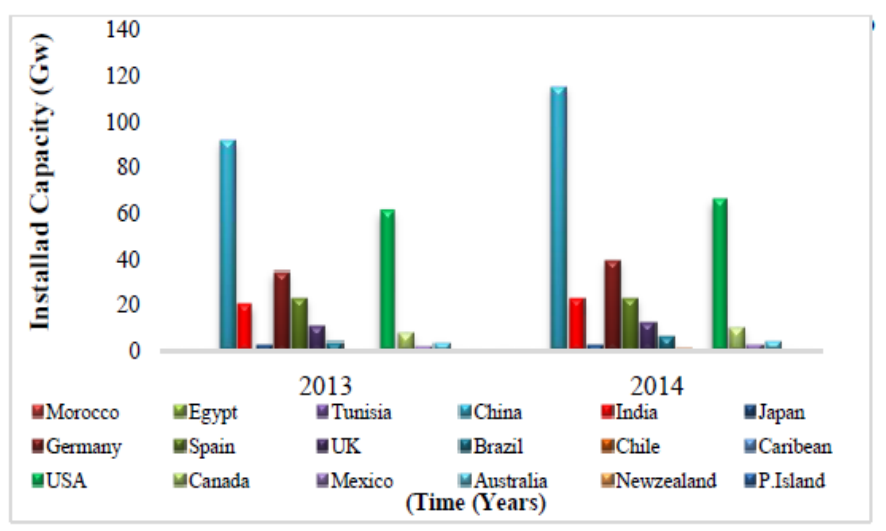

Fig. 2. Top countries wind installed capacity in FY 2013-2014.

The manuscript is divided into seven sections. The rest of the sections are described as follows:

A machine model is described in Section 2. The aerodynamic model of wind turbine rotor is briefly reviewed in Section 3. The $\mathrm{C}_{\mathrm{p}}$ and tip speed ratio model is discussed in Section 4. A brief discussion of wind turbine model is discussed in Section 5. Power Transmission network Model and in Simulation example in order to verify the effectiveness of the proposed control systems for WECS are presented in Sections 6 and 7, respectively. Finally, the conclusion and future work has been summarizing in Section 8 .

\section{MACHINE MODEL}

In the proposed system, authors considered a squirrel-cage induction generator (SCIG) which is relatively cheap, reliable, and efficient machines than others when operated through vector control techniques [13]. However, the equivalent circuit diagram of SCIG can be visualized in Fig. 3. Moreover, from the equivalent circuit model of the SCIG, the voltage equations in the $(d q)$ arbitrary reference frame are given as follows:
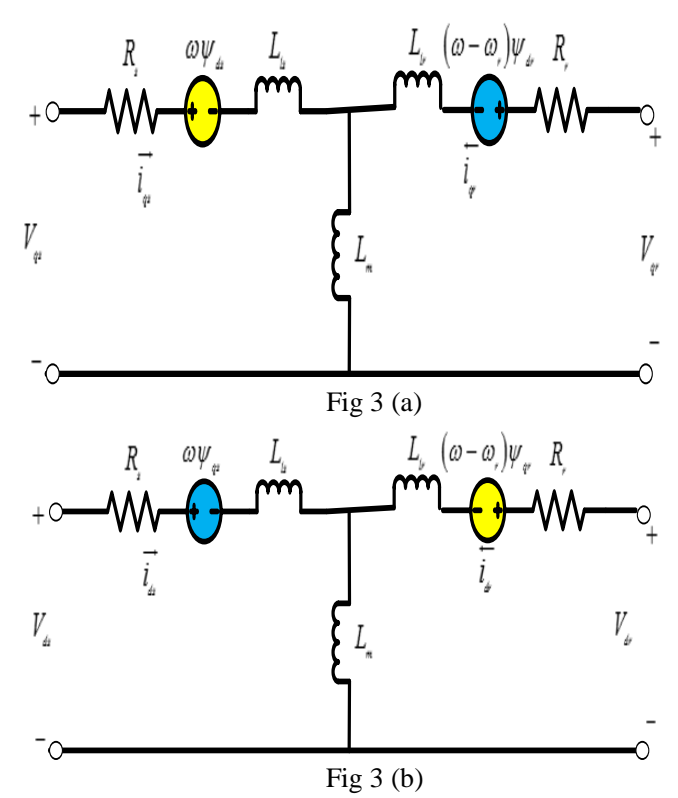

Fig. 3. Equivalent circuit diagram of SCIG in $q d$-axis reference frame.

- Stator voltage model in $d q$-frame:

$$
\begin{aligned}
& V_{q s}+R_{s} i_{q s}+\omega_{s} \psi_{d s}=\frac{d \psi_{q s}}{d t} \\
& V_{d s}+R_{s} i_{d s}+\omega_{s} \psi_{q s}=\frac{d \psi_{d s}}{d t}
\end{aligned}
$$

Rotor voltage model in $d q$-frame:

$$
\begin{aligned}
& R_{r} i_{q r}-s \omega_{s} \psi_{d r}=\frac{d \psi_{q r}}{d t} \\
& R_{r} i_{d r}+s \omega_{s} \psi_{q r}=\frac{d \psi_{d r}}{d t}
\end{aligned}
$$

The $(d q)$ frame is rotating at the synchronous speed around 90-degree quadrature axis leading to the direct axis. Furthermore, the flux linkages in (1)-(2), can be estimated as given below:

Stator and rotor flux model in $d q$-frame:

$$
\begin{aligned}
& \psi_{d s}=-L_{m} i_{d r}-L_{l s} i_{d s}-i_{d s} L_{m}, \\
& \psi_{q s}=-L_{m} i_{q r}-L_{l s} i_{q s}-i_{q s} L_{m} \\
& \psi_{d r}=-L_{m} i_{d s}-L_{l s} i_{d r}-i_{d r} L_{m}, \\
& \psi_{q r}=-L_{m} i_{q s}-L_{l s} i_{q r}-i_{q r} L_{m}
\end{aligned}
$$

From (1)-(4) we have: $s=\left(\omega_{s}-0.5 p \omega_{m}\right) \omega_{s}^{-1}$, and $p=$ No. of poles; $\omega_{m}=$ Mechanical frequency of the generator in $(\mathrm{rad} / \mathrm{s}) ; V=$ Voltage; $R=$ Resistance; $i=$ Current; $\psi=$ Flux linkage; $\omega=$ Electrical frequency; $L_{m}=$ 
Mutual inductance; $L_{l}=$ Leakage inductance, in (1)-(4), s and $\mathrm{r}$ subscript shows the stator and rotor, whereas $d q$ shows the direct and quadrature-axis components. Furthermore, the generated active (P)/reactive (Q) power through the SCIG can be expressed as follows:

$$
\begin{aligned}
& P_{s}=V_{q s} i_{q s}+V_{d s} i_{d s}, \\
& Q_{s}=V_{q s} i_{d s}-V_{d s} i_{q s}
\end{aligned}
$$

Moreover, it is concluded that the stator winding of the electrical generator is connected to the power grid through the power converter. The active and reactive power fed into or drawn from the power grid can be estimated and used in the simulation by using (5). However, the electromechanical sections must be included in a dynamic system model for utilizing in power dynamic simulations.

The electromechanical torque and speed produced by SCIG is:

$$
\begin{aligned}
& T_{e}=\psi_{d s} i_{q s}-\psi_{q s} i_{d s}, \\
& \frac{d \omega_{r}}{d t}=\frac{1}{J_{g}}\left(T_{L}-T_{e}\right)
\end{aligned}
$$

Where, $T_{L}$ is the load torque, and $J_{g}$ is the generator inertia constant.

\section{AERODYNAMIC MODEL}

The wind power generated by the wind energy, and mechanically power extracted from the wind turbine is assumed as follows [13]:

$$
P_{\omega}=\frac{1}{2} \rho \pi R^{2} V_{\omega}^{3},
$$

From (7), $R=$ length of turbine in (m), $\rho=$ wind density in $\left(\mathrm{kg} / \mathrm{m}^{3}\right)$, and $V_{\omega}=$ wind speed in $(\mathrm{m} / \mathrm{sec})$.

The algebraic relation between aerodynamic turbine torque $T_{t}$ and wind turbine power $P_{t}$, defined as the function $V_{\omega}$ and $\lambda_{c}$ including $\omega_{t}$ as described by the following relation:

$$
\begin{gathered}
P_{t}\left(\omega_{t}, V_{\omega}\right)=\omega_{t} T_{t} \\
\text { IV. } \mathrm{C}_{\mathrm{P}} \text { AND TIP SPEED RATIO MODEL }
\end{gathered}
$$

The $\mathrm{C}_{\mathrm{p}}$ and TSR model is defined by the following relation:

$$
C_{p}\left(\omega_{t}, V_{\omega}\right)=\frac{1}{P_{\omega}} T_{t} \omega_{t}
$$

From (9), $C_{p}$ is the dimensionless factor, and equal to the ratio of $P_{t}$ to the $P_{\omega}$. Basically, $C_{p}$ is a function of $\omega_{t}$ and $V_{\omega}$. According to the Betz law, the $C_{p}$ theoretical limit is 0.59 but the practical limit is $0.2-0.4$ (see [14]). The $C_{p}$ has been numerically estimated and can be described as follows:

$$
C_{p}\left(\omega_{t}, V_{\omega}\right)=0.73\left(151 \frac{1}{\lambda_{c}}-0.58 \delta-0.002 \frac{1}{\delta^{-2.14}}-13.2\right) \mathrm{e}^{-\left(18.4 \frac{1}{\lambda_{c}}\right)}
$$

However, the $C_{p}$ depends on the $\omega_{t}$, which might be used for wind turbine stability and control. $\delta$ is the pitch angle (see [15]), the main function of the pitch system is to maintain the turbine torque at the rated wind speeds, and $\lambda_{c}$ is the ratio of linear speed at the tip of blades to the $V_{\omega}$ and can be described as follows:

$$
\frac{1}{\lambda_{c}}=\left(\frac{1}{\lambda-0.002 \delta}-\frac{0.003}{\delta^{3}+1}\right), \text { where } \lambda=\frac{\omega_{t} R}{V_{\omega}},
$$

From (7)-(11), we have:

$$
P_{t}\left(\omega_{t}, V_{\omega}\right)=14.33 V_{\omega}^{3}\left(151 \frac{1}{\lambda_{c}}-0.58 \delta-0.002 \delta^{2.14}-13.2\right) \mathrm{e}^{-\left(18.4 \frac{1}{\lambda_{c}}\right)}
$$

Equation (12) shows the wind turbine power captured by the turbine is a sole function of the wind turbine speed and wind speed. However, $V_{\omega}=$ input disturbance and $\omega_{t}$ is regulated to govern the WT with the bounded stable condition.

\section{WIND TURBINE MODEL}

Modeling is a basic tool for investigating any system, for example wind turbine design, optimization, control, reliability, and stability. Basically, wind turbine systems are unlike than conventional type turbine systems, and consequently, dynamic wind turbine system must be employed in order to integrate with the electrical network. In addition, several models are suitable for WTs depending on the various factors such as size, blade radius, nominal power, shaft stiffness, losses, spring damper, gear box ratio, etc. [13]. Fig. 4 is the schematic diagram of a WT shaft including with spring damper. The WT shafts including mechanical gearbox model is described here.

The WT position and speed model with turbine power relation is given as follows:

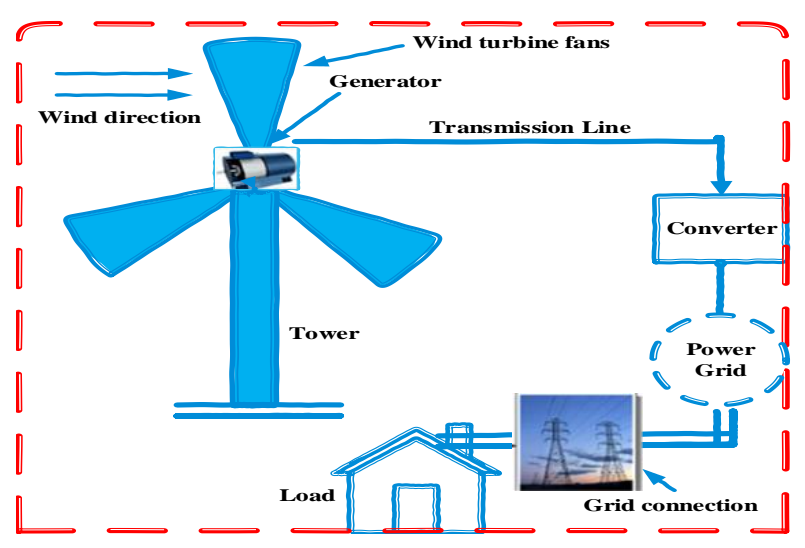

Fig. 4. A schematic diagrams of the WTGS including gearbox. 


$$
\begin{aligned}
& \frac{d}{d t} \theta=\omega_{t}-\frac{1}{g p} \omega_{r} ; \text { where } \theta=\theta_{t}-\frac{1}{g p} \theta_{r} \\
& \frac{d}{d t} \omega_{t}=-\frac{1}{J_{t} \omega_{t}} P_{t}\left(\omega_{t}, v_{\omega}\right)-\frac{1}{J_{t}} T_{L} \\
& T_{L}=\left\{D_{r}\left(\omega_{t}-\frac{\omega_{r}}{g p}\right)+Q_{s} \theta\right\}
\end{aligned}
$$

Where, ${ }^{\theta_{t}}=\mathrm{WT}$ angle; $\theta_{r}=$ rotor electrical angle of IG; $Q_{s}=\mathrm{WT}$ spring stiffness coefficient; $\boldsymbol{D}_{r}=\mathrm{WT}$ damping factor; and $J_{t}$ WT inertia.

\section{POWER TRANSMISSION NETWORK MODEL}

The $d q$ dynamic system model of the power transmission network model is described as follows:

$$
\begin{gathered}
V_{q s}=V_{q b}+R_{P T L} i_{q_{P T L}}+X_{P T L} i_{d_{P T L}}+\frac{d X_{P T L}}{\omega_{b} d t} i_{q_{P T L}} \\
V_{d s}=V_{d b}+R_{P T L} i_{d_{P T L}}-X_{P T L} i_{q_{P T L}}+\frac{d X}{\omega_{b T L} d t} i_{d_{P T L}}
\end{gathered}
$$

Where, $V_{b}$ is the bus voltage, $R_{P T L}$ is the resistance of power transmission line $i_{P T L}$ is the current of power transmission line $X_{P T L}$ is reactance of power transmission line.

\section{Simulation Results PERFORMANCE}

The simulation results verify the effectiveness of the proposed control design for WECS based on SCIG with the help of static voltage compensator. The static voltage compensator is simple in construction and well known for power system which is employed to compensate the dynamic system parameters in efficient way. However, the better performance and improvement in dynamic system is our main effort for wind energy conversion system along with system harmonics. The root locus of the whole is shown in Fig. 5.

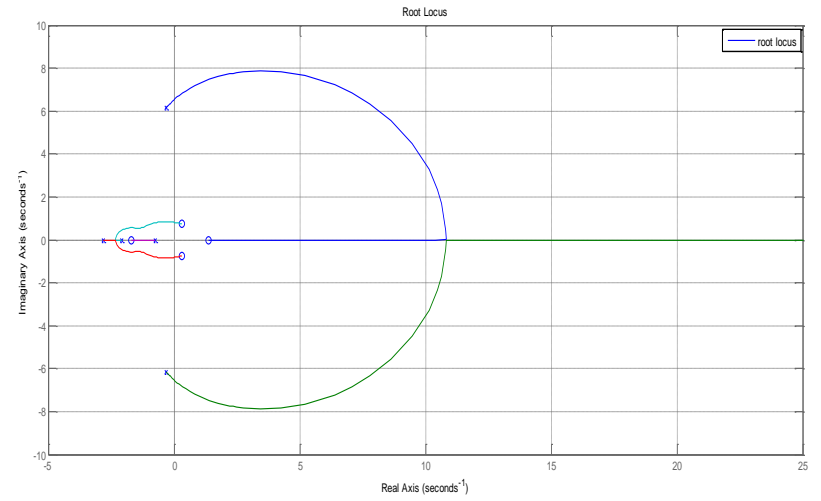

Fig. 5. Root locus response versus time.

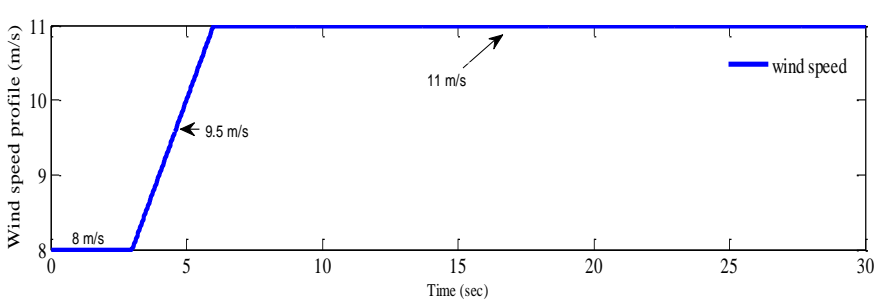

Fig. 6. Wind speed profile response versus time.

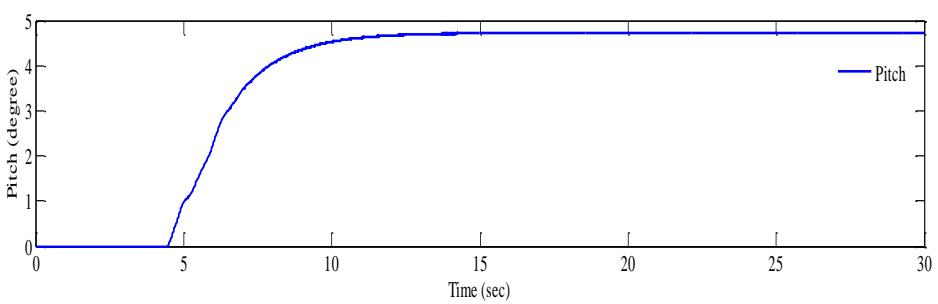

Fig. 7. Pitch angle response versus time.

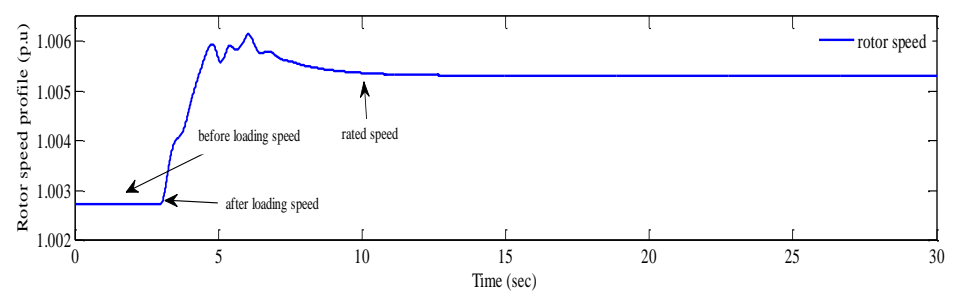

Fig. 8. Rotor speed response versus time.

Initially when $\mathrm{t}<3 \mathrm{ec}$; the wind speed is $8 \mathrm{~m} / \mathrm{sec}$, after that when $t=3 \mathrm{sec}$, the wind speed starts to shoot up (see Fig. 6), and it reaches at rated level after $\mathrm{t}=6 \mathrm{sec}$ approximately. And the total estimated time duration is $30 \mathrm{sec}$. in the same way, the pitch angle was observed as shown in Fig. 7.

In the same way, the rotor speed is at the constant level when $\mathrm{t}<3$, around less than 1 p.u, and after 3 seconds, the rotor speed starts shoot up (see Fig. 8), for few micro seconds there is some oscillation due to machine saturations. In addition, when after time $t=8 \mathrm{sec}$, the rotor speed was compensated to its rated values as it's clearly visualized in Fig. 8.

The system voltage was observed through voltage source compensator. Around $10 \mathrm{sec}$ later, the system voltage was compensated and stabilize the dynamic system and can be easily visualize in Fig. 9.

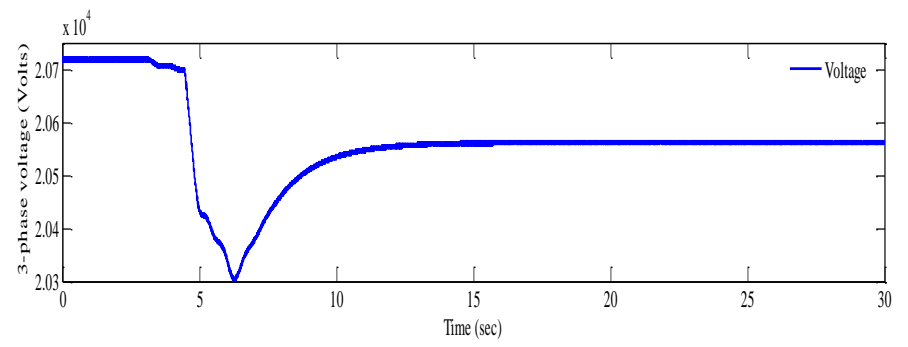

Fig. 9. Three phase voltage response versus time. 


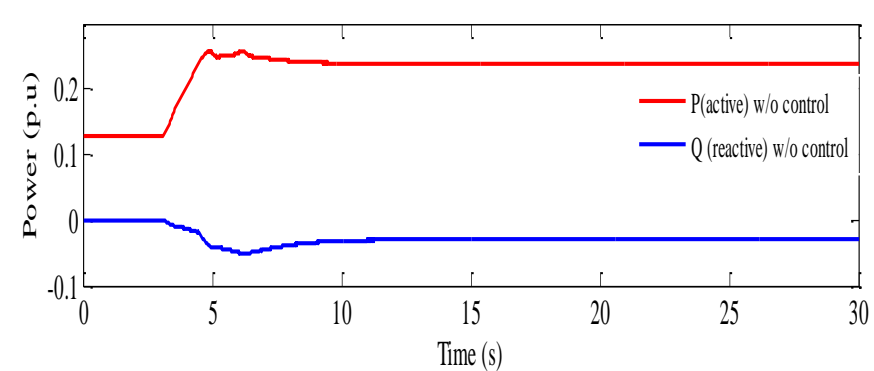

Fig. 10. Power without control (w/o compensator) response versus time.

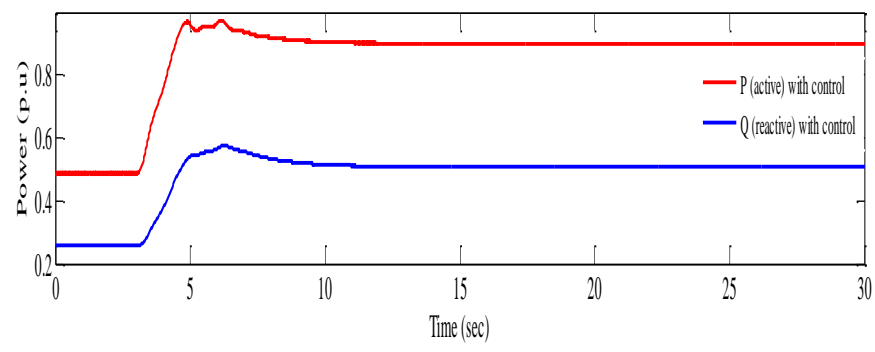

Fig. 11. Power with control (compensator) response versus time.

Initially when $\mathrm{t}<3 \mathrm{ec}$; the active and reactive power is approx. 0.13 p.u and zero p.u respectively, with respect to wind speed as shown in Fig. 10, after that when $t=3 \mathrm{sec}$, the power starts to goes up and it reaches at max level, after time $t$ $=6 \mathrm{sec}$, the active and reactive power is stable and compensated as demanded. Moreover, based on the compensator the power can boost up to its rated values as shown in Fig. 11.

At the end, we have estimated and observed FFT analysis of the system at fundamental frequency as shown in Fig. 12. The total harmonic distortion is approximately 16.4 per cent that is affordable for the dynamic nonlinear system.

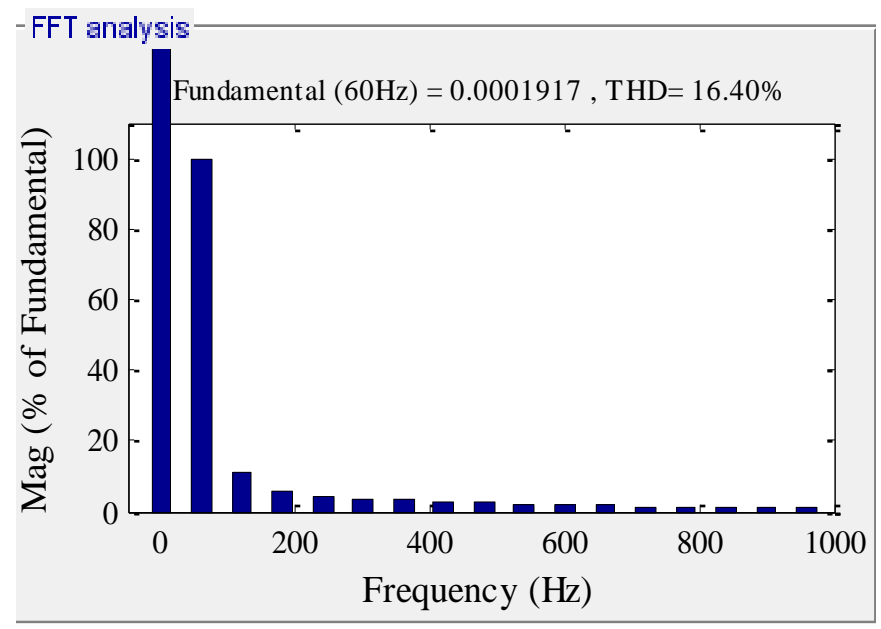

Fig. 12. THD estimation through FFT analysis.

Finally, the simulated outcomes have verified that the intended design scheme carried out realistically sound in practice and goal is achieved under system disturbances at uncertain wind speed. Hence, it's proved that the proposed controller solution concept is more suitable for wind energy conversion system applications.

\section{CONCLUSIONS}

A dynamic WT model based on SCIG with VS wind energy conversion system has been analyzed and simulated through Matlab using voltage compensator controller with the acceptable condition of the scheme factors. It is evidently witnessed from the simulation outcomes that the author's proposed controller have an effective performance regarding boosting the power and eliminates the dynamic system harmonics.

\section{FUTURE RECOMMENDATIONS}

Ongoing and future works consist of a nonlinear controller design for wind turbine system stability algorithm can enthusiastically be comprehensive to another category of WTS parameter with no major modifications. The current study still needs the state of the art research efforts with real time challenge for dynamic wind turbine system application. Safety, security, monitoring and an effective stability and control of WECS should be a hot topic for advance research.

\section{ACKNOWLEDGEMENTS}

Authors are highly acknowledged to Electrical Engineering department of Mehran University of Engineering and Technology Pakistan, Higher Education Commissions Pakistan and Shanghai Jiao Tong University P R China for their morally support.

\section{APPENDIX}

The WGS parameters constant values with their standard units are described as follows (Table 1):

TABLE I. SCIG AND WIND TURBINE CONSTANT PARAMETERS VALUES

\begin{tabular}{|l|l|l|l|}
\hline Nominal Power & 3.7 kwatts & p & 2 poles \\
\hline Voltages & 460 Volts & $\mathrm{g}$ & 20 \\
\hline $\mathrm{L}_{\mathrm{m}}$ & 1.35 p.u & rho & $1.25 \mathrm{~kg} / \mathrm{m}^{3}$ \\
\hline $\mathrm{J}$ & 0.09526 p.u & $\mathrm{R}_{\mathrm{s}}$ & 0.01965 p.u \\
\hline $\mathrm{L}_{\mathrm{lr}}=\mathrm{L}_{\mathrm{ls}}$ & 0.0397 p.u & $\mathrm{R}_{\mathrm{r}}$ & 0.01909 p.u \\
\hline $\mathrm{L}_{\mathrm{s}}=\mathrm{L}_{\mathrm{m}}+\mathrm{L}_{\mathrm{ls}}$ and $\mathrm{L}_{\mathrm{r}}=\mathrm{L}_{\mathrm{m}}+\mathrm{L}_{\mathrm{lr}}$ &
\end{tabular}

\section{REFERENCE}

[1] H.-J. Wagner and J. Mathur, Introduction to wind energy systems: basics, technology and operation: Springer Science \& Business Media, 2012.

[2] H. M. Nguyen and D. S. Naidu, "Advanced control strategies for wind energy systems: an overview," in Power Systems Conference and Exposition (PSCE), 2011 IEEE/PES, 2011, pp. 1-8.

[3] O. Barambones, J. M. G. De Durana, P. Alkorta, J. A. Ramos, and M. De La Sen, "Sliding mode control law for a variable speed wind turbine," WSEAS Transactions on Systems and Control, vol. 6, pp. 4453, 2011.

[4] J. Hui and A. Bakhshai, "A new adaptive control algorithm for maximum power point tracking for wind energy conversion systems," in Power Electronics Specialists Conference, 2008. PESC 2008. IEEE, 2008, pp. 4003-4007. 
[5] B. Consult, International Wind Energy Development: Supply Chain Assessment 2012: Forecast 2012-2015: BTM Consult, 2011.

[6] T. Ackermann and L. Söder, "Wind energy technology and current status: a review," Renewable and sustainable energy reviews, vol. 4, pp. 315-374, 2000.

[7] A.I. Bratcu, I. Munteanu, E. Ceangă, and S. Epure, "Energetic optimization of variable speed wind energy conversion systems by extremum seeking control," in EUROCON, 2007. The International Conference on \&\# 34; Computer as a Tool\&\# 34;, 2007, pp. 2536-2541.

[8] W.-L. Chen and Y.-Y. Hsu, "Controller design for an induction generator driven by a variable-speed wind turbine," Energy Conversion, IEEE Transactions on, vol. 21, pp. 625-635, 2006.

[9] L. A. Lopes and R. G. Almeida, "Wind-driven self-excited induction generator with voltage and frequency regulated by a reduced-rating voltage source inverter," Energy Conversion, IEEE Transactions on, vol. 21, pp. 297-304, 2006.

[10] Y. Kazachkov, J. W. Feltes, and R. Zavadil, "Modeling wind farms for power system stability studies," in Power Engineering Society General Meeting, 2003, IEEE, 2003.

[11] A.E. Feijoo and J. Cidras, "Modeling of wind farms in the load flow analysis," IEEE transactions on power systems, vol. 15, pp. 110-115, 2000.

[12] K. E. Johnson, L. Y. Pao, M. J. Balas, and L. J. Fingersh, "Control of variable-speed wind turbines: standard and adaptive techniques for maximizing energy capture,” Control Systems, IEEE, vol. 26, pp. 70-81, 2006.

[13] M. H. Baloch, J. Wang, and G. S. Kaloi, "Stability and nonlinear controller analysis of wind energy conversion system with random wind speed," International Journal of Electrical Power \& Energy Systems, vol. 79, pp. 75-83, 2016.

[14] P. C. Krause, O. Wasynczuk, S. D. Sudhoff, and S. Pekarek, Analysis of electric machinery and drive systems vol. 75: John Wiley \& Sons, 2013.

[15] B. Beltran, T. Ahmed-Ali, and M. E. H. Benbouzid, "Sliding mode power control of variable-speed wind energy conversion systems," Energy Conversion, IEEE Transactions on, vol. 23, pp. 551-558, 2008.

[16] Sarwar Kaloi, Ghulam, Jie Wang, and Mazhar H. Baloch. "Study of stabilty analysis of a grid connected doubly fed induction generator based on wind energy Application." Indonesian Journal of Electrical Engineering and Computer Science 3.2 (2016): 305-313.

[17] Baloch, Mazhar H., Ghulam S. Kaloi, and Zubair A. Memon. "Current scenario of the wind energy in Pakistan challenges and future perspectives: A case study." Energy Reports 2 (2016): 201-210.

[18] Baloch, Mazhar H., et al. "A Research on Electricity Generation from Wind Corridors of Pakistan (Two Provinces): A Technical Proposal for Remote Zones." Sustainability 9.9 (2017): 1611.

[19] Kaloi, Ghulam Sarwar, et al. "Wind Energy Potential at Badin and Pasni Costal Line of Pakistan." International Journal of Renewable Energy Development 6.2 (2017). 